Paediatrica Indonesiana 15:105 - 111. March-April 1975. 105

Vice Director, Tokyo Ebara Municipal Hospital Guest

Professor, Showa Medical University

\title{
Treatment of Newborns and Infants in Japan suffering from Pneumonia with New Antibiotics
}

$b y$

\author{
SUSUMU NAKAZAWA
}

\begin{abstract}
Despite the recent development of a high statie of chemothenapy in Japan, there has not necessiarily bien an improvement in the proginasis of pineumionia in infiants and newborns.

Upon bacteriological examination, relevant causative organisms such as pathogenic staphylococci, pneumococci, streptococci, amid gram-neglative bacteria have beien detected as axusing mixad infection.

Suitiable chemotherapatic agents which aliffuse well to the hong and show high bactericidal action agarinst such onganisms must be selected to combat the infection.

A comibination of two synthetic panioillins, ampicithin, effective against gram inegative as well as gram-pasitive bacteria and cloxacillin effective agrainst resistant staphylococci, was used for the treatment of many cases of pneumonia in infants and newborns and satisfactory results were obtiained.
\end{abstract}

The results of this study and anappraisal of penicillin combination thenoipy will be discussed.

Presented at the Third National Indonesian Pediatric Congress, Surabaya July $1-6,1974$. 
Prog $n_{0 \text { sis }}$ of newborns and infants sufferimg from pneumonia in Japan has not significantly improved despite the development of new antibiotics.

Thils is attributed to various factors including the low natural defense in the young, their greater susceptibility to virus infections, and increasing drug resistance of causative organisms.

I wish to repont here on the prog. nosis of premature and newborn babies suffening from pneumonia who were treated at universities and other large hospitals in Japan. The main causative organisms involved in pneumonia among the young are disted in itable 2.

Of late, there has been an increase in complicating infections due to Haemophillus, Escheria coli and other gram-negative bacteria (GNB), in addition to pathogenic Staphylococcus, pneumococcus and beta-Streptococcus. It is therefore necessary to give preference to centain antibiotics having the following descriptions:

1. Broad spectrum antibilotics effective against cocci and bacilli, including Staphylococcus and GNB which have little or no sensitivity to antibiotics.

2. Bactericidal antibiotaica.

3. Antibiotics which feature high concentrations in the blood and other body fluids and in various organs, resulting in a strong antibacterial effect.

4. Antibiotics which feature few side-effects when administered to children, even parenterally.

The following antibiotics now used in Japan meet these requirements:

1. Synthetic penicillins and their combined preparations.

2. Aminoglycoside antibiotics ( $\mathrm{Ka}$ namycin, Kanendomycin, etc.).

3. Cephalosporins (CP).

Many pathogenic Staphylococci isolated in Japan have of late been found resistant to Penicilline $G$ (Pc.G), Tetracycline (TC), Streptomycine (SM) and CP.

We made a study of the prognosis of pneumonia among newborn and premature babies treated at childrens' hospitals in Tokyo with Cloxacillin (MCT-Pc) or Oxacillin(MPI$\mathrm{Pc})$ both of which are synthetic PCs and effective against resistant Staphylococai. These were compared with prognosis of similar cases treated with conventional antibiotics. Prognosis of group treated with synthetic PCs effective against resistant Staphylococci was found to be superior. (Table 3 dan 4).

Then Viccillin $S$, a combination of Closacillin and Ampicillin, which is effective againat GNB, became available, and we began to use it exciusively (Table 5). The reasons for this are as follows: 
1. The antimicrobial spectrum of the two antibuiotics forming the Viccillin $\mathbf{S}$ combination is broadened through synergistic action, and therefore the combination is effective against almost all cocci and GNB.

2. Antibacterial effect after in. jection is good because satisfactory levels of concentration are attained.

3. It is possibile to commence treatment before the causative organisms are identified due to the broadened spectrum of this combination, which is especially helpful in the case of pneumonia in infancy where early treatment is of great impor. tance.

We have treated many cases of pneumonia in infancy usling Viccillin $S$ as the main antibiortic. I will report here on part of the results.

A daily dosage of 100 to $250 \mathrm{mg}$ / $\mathrm{kg}$ was injected in two or three diviided doses for 7 to 10 or more consecutive days. This treatment was effective in $88 \%$ of the 54 cases involved. Severe side-effects of synthetic penicillin in young children are very rare, and in our study no side-effects were observed. However, a tesit for hypersensitive reaction to penicillin is advisable prior to administration.
Kanendomycin, an aminoglycoside antibiotic recently developed in $\mathrm{Ja}$ pan, is now also being used to treat pneumonia in infants. Produced by a mutant stralin of Streptomyces kanamycelticus, it has a greater inhibitory effect than Kanamycin against Staph. or E. coli which are resistant to many other antibiotics. Distribution of thils antibiotic to the organs after injection was very good. Its MIC against recently isolated Staphylococcus was 0.39 to $0.78 \mathrm{mcg} /$ $\mathrm{ml}$ and against $\mathrm{E}$. coli 0.78 to 3.12 $\mathrm{mcg} / \mathrm{ml}$. Its mean bllood levels were $34.8 \mathrm{mcg} / \mathrm{ml}$ at one hour, 28.2 at three hours, 27.9 at six hours and 9.8 at twellve hours after intramuscular injection of $10 \mathrm{mg} / \mathrm{kg}$ to newborn babies.

Administration of 5 to $15 \mathrm{mg} / \mathrm{kg}$ per day for periods of 7 to 10 days was clinically effectilve against Staphylococcal pneumonia in almost all cases. No 8 th cranial nerve or kidney disordens were observed when administration lasted less than itwo weeks.

Finally, I would like to show you the results of cases of pneumonia in infants treated at a Japanese university with various antibiotics. (Table 1). It can be seen that synthetic penicillin demonstrated the greatest effectiveness. 
TABLE 1 : Results of Infantile pneumonia treated with various antibiotics $(1957-1966)$.

\begin{tabular}{lcccccccc}
\hline & $\begin{array}{c}\text { Synthetic } \\
\text { Pc. }\end{array}$ & KN & $\begin{array}{c}\text { KM } \\
+ \\
\text { PC. G. }\end{array}$ & CER & CET & TC & CP & Others \\
\hline $\begin{array}{l}\text { No. of cases } \\
\begin{array}{c}\text { Effective rate } \\
(\%)\end{array}\end{array}$ & 11 & 18 & 13 & 14 & 6 & 20 & 49 & 18 \\
\hline
\end{tabular}

TABLE 2 : Cansative Orgaitisms of pneumonia in infancy (Nov. 1957. Dec. 1965).

\begin{tabular}{lccccccc}
\hline $\begin{array}{l}\text { (No. of } \\
\text { cases) }\end{array}$ & $\begin{array}{c}\text { Beta- } \\
\text { Strept. }\end{array}$ & $\begin{array}{c}\text { Coag( }+) \\
\text { Staph. }\end{array}$ & $\begin{array}{c}\text { Pneumo- Haemoph. } \\
\text { cocci } \\
\text { Inf. }\end{array}$ & $\begin{array}{c}\text { Gram(-) } \\
\text { Bacilli }\end{array}$ & Pseud. & Proteus \\
\hline 166 & $\begin{array}{c}13 \\
(7.8 \%)\end{array}$ & $\begin{array}{c}62 \\
(37.2 \%)\end{array}$ & $\begin{array}{c}23 \\
(13.8 \%)\end{array}$ & $\begin{array}{c}15 \\
(9.0 \%)\end{array}$ & $\begin{array}{c}32 \\
(19.2 \%)\end{array}$ & $(7.8 \%)$ & $(2.4 \%)$ \\
\hline
\end{tabular}



$\begin{aligned} & \text { FIG. } 6: \text { DHF hospitalized cases and deaths, Children's Hospital, } \\ & \text { Bangkok }\end{aligned}$

CHLDREN'S HOSPTAL DENGUE HEMORRHAGIC FEVER.

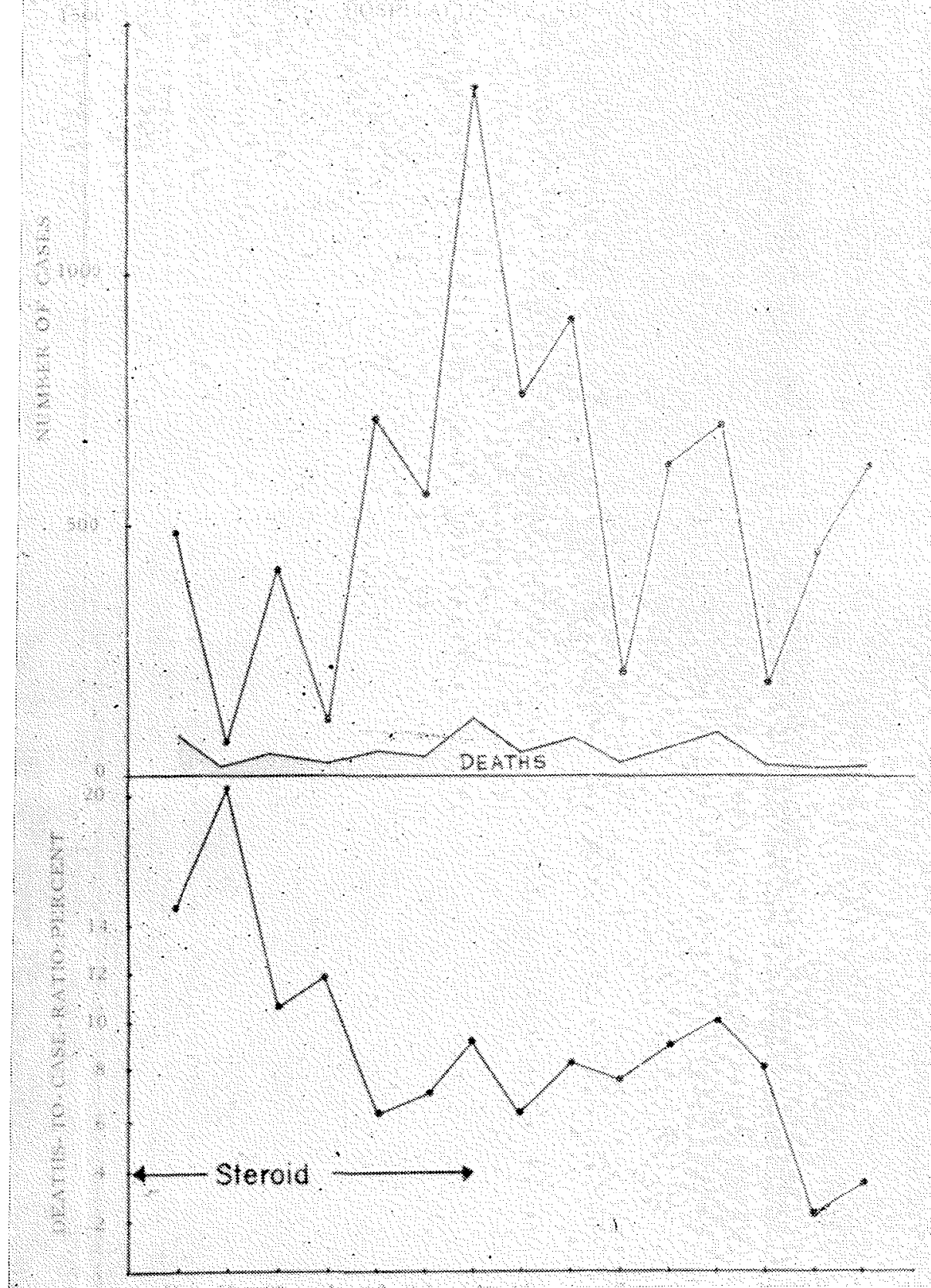




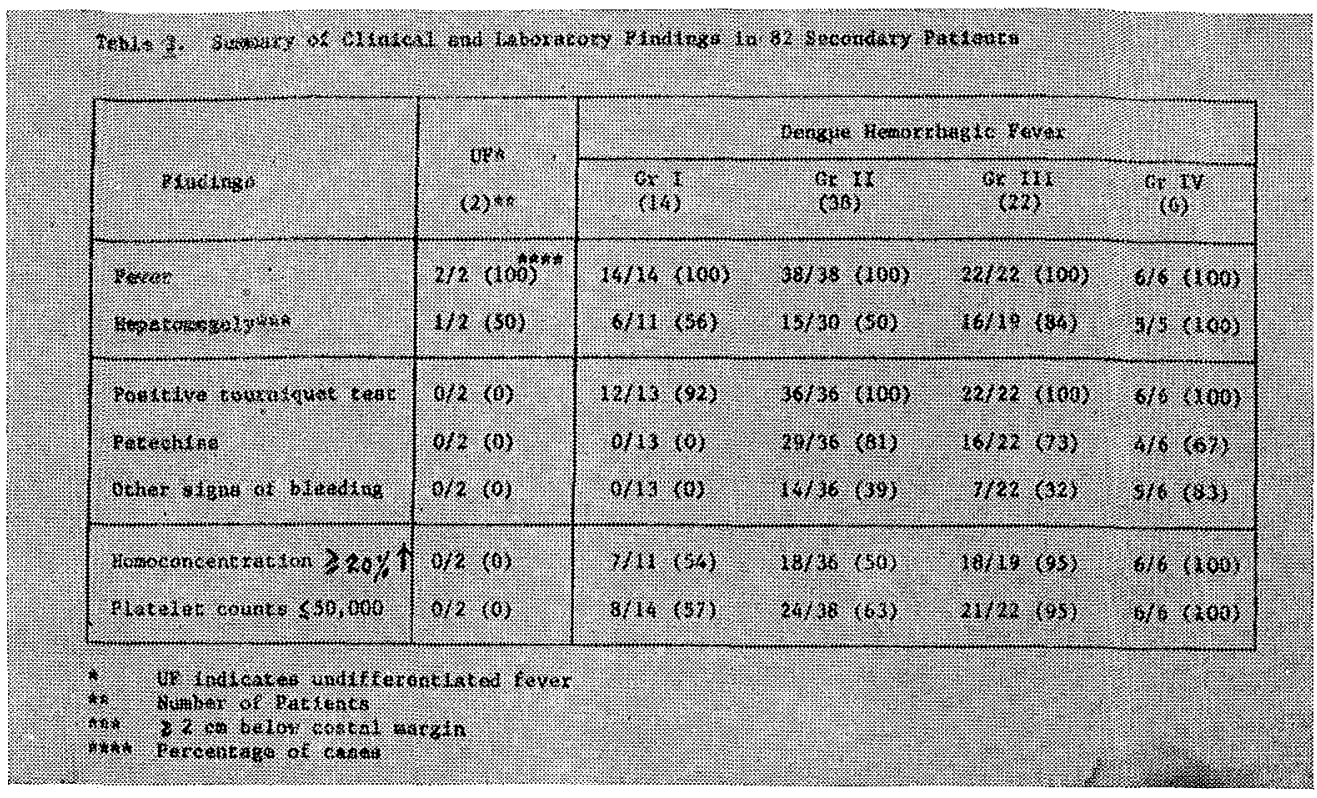

TABLE 2: Clotting studies in dengue hemorrhagic fever

\begin{tabular}{|c|c|c|c|c|}
\hline & Result V.s. & Disease & Severity & \\
\hline 1est & $\operatorname{gr} I$ & $\underset{(14)}{\operatorname{gr} I I}$ & $\underset{(22)}{\operatorname{gr} I I I}$ & $\underset{(12)}{\operatorname{gr~IV~}}$ \\
\hline $\begin{array}{l}\text { Fibrinogen } \mathrm{gm} / \mathrm{Lt} \\
\text { average minimum level } \\
\text { (Control } 1.72 \mathrm{gm} / \mathrm{Lt} \text { ) }\end{array}$ & 1.51 & 1.20 & 0.98 & 0.89 \\
\hline $\begin{array}{l}\text { Fibrinogen degradation product } \\
\text { (percent present) }\end{array}$ & 37.0 & 41.0 & 51.0 & 53.0 \\
\hline $\begin{array}{l}\text { The average amount of split pro- } \\
\text { ducts }(\mathrm{mg} / 100 \mathrm{ml}) \text {. }\end{array}$ & 1.7 & 3.2 & 2.9 & 5.1 \\
\hline $\begin{array}{l}\text { Platelet counts } \\
\text { (average lowest counts) }\end{array}$ & 59,00 & 49,000 & 24,000 & 20,000 \\
\hline
\end{tabular}

WHO Bulletin, 1973, 48. 
viral proteins. The amount of antigen sharing, however, is not sufficient to provide cross protection, thus infection with one sero-type may be followed by infection with a heterologous serotypes (Sabin, 1952; Whitehead et al., 1970).

The virus associated with DHF includes all four serotypes of dengue viruses. An intruguing paradox exists in view of the fact that these same also cause classical dengue fever and benign undifferentiated febrille illness in some endemic and epidemic situations. There are no demonstrable major antigenic differences between dengue strains of the same serotypes causing milld dengue illness and severe DHF (Russell and Nisalak, 1967); each of the four serotypes is capable of producing benign or severe diseases, depending on the epidemic situations.

Extensive epidemiological studies have convincingly demonstrated that DHF occurs where two or more dengue serotypes are simultaneously endemic or sequentially epidemics and where ecological condititions favor efficient virus transmission by the vector mosquitoes. As man is the only significant dengue host and Ae. aegypti the important vector, both the ecological conditions of man and mosquitoes are basic ingredients for DHF outbreak.

Serological studies revealed the association of DHF and DSS with the secondary type antibody response.
Fig. 1 shows the age distribution curve of DHF patients admitted to the Children's Hospital, Bangkok, during the $1962-1964$ outbreaks. There were two modal ages, less than one year and 4 years old; $86 \%$ of these werc children with secondary dengue infection whose age grouped around the mode of 4 years. The rest were those with primary infection predominantly infants under one year old (Fig. 2). The incidence of shock in the group with secondary antibody response of $40 \%$ is significantly different from $8 \%$ observed in the group with primary infection.

These epidemiological and serologic observations implicating "the two infection hypothesis" of the pathogenesis of DHF. It has been postulated that during a secondary infection with a dengue virus different from the one that caused the primary infection, an enhanced immunological responise plays a central role in disease pathogenesis, through a mechanusm which has not been clearly demonstrated (Halstead et al., 1967). The inicidence of shock in primary infection, however, remains an enigma. It is dikely that in infants under one year of age, passive immunity antidengue IgG antibody from mother, at very low titer is capabile of enhancing the ofmmunological sequence as in secondary infection.

It is of interest to note that in Thailand, dengue 2 viruses have been isolated in higher frequency than 
other serotypes from cases with secondaxy antibody response while the proportion of dengue 1,2 and 3 viruses recovered from mosquitoes and patients with primary dengue infection were nearly equal (Halstead et al., 1970). These observations raised the major question related to correlation of disease severity and the infecting dengue serotypes.

The basic epidemiological conditions essential to the occurrence of DHF appear to be the presence of two or more dengue virus serotypes and a high rate of transmission. The interval between sequential infections may be also an impontant factor. The fact that no DHF or DSS was observed in Puerto Rico, where two sequential epidemics of dengue occurred in 1963 and 1969 with dengue 3 and dengue 2 respectivelly, suggest that two infections six years apart produce different results than two infections at a shorter interval (within 5 years) as observed in Thailland (Winter et al., 1969; Fischer and Halstead, 1970).

\section{Clinical Aspect}

The clinical spectrum of DHF ranges from mild dengue fever like, to the life threatening illness with shock. (Fig. 3). In typical cases, the disease is characterized by four maor manifestations, high fever, various hemorrhagic diathesis most commonly skin hemorrhages, hepatomegaly and circulatory disturbance in the form of shock severe cases.
The course of a patient with DHF typicalily consists of an early febrile period lasting from two to seven days. Anorexia and vomiting are common findings which may contribute to some fluid and electrolyte discurbance.

Hemorrhagic diathesis, most commonly as skin hemorrhage: positive tourniquet test, petechial rash are seen frequently in the early phase of illness. Hemorrhages sometimes may be severe and even fatal; gastrointestinal bleedings as hematemesis and/or melena, when present, often occurs afiter the onset of shock, more often after prolonged uncontrolled shock.

Hepatomegaly - Enlargement of the liver occurs frequently. The liver may be palpable early in the febrile phase or appears later when the patient became afebrile. A big tender liver is common but jaundice is not usually found.

In a severe case, following fever of 8. few days duration the patients condition suddenly deteriorates. Accompanying or shortly after the fall in temperature at the end of febrile period, there are signs of circulatory failure; the skin becomes cool, blotchy and congested, circumoral cyanosis is frequentily observed and the pulse becomes rapid. Although in some cases they may appear lethargic, patients become restless and then rapidily go into a critical stage of shock. Abdominal pain is a frequent 
TABLE 3 : Prognosis of pneumonia in meutiorn and premaiure babies $(195 \%$ - 1967).

(Total: 213 cases)

\begin{tabular}{|c|c|c|c|c|}
\hline \multirow{2}{*}{ Institutes } & \multicolumn{2}{|c|}{ Newborn } & \multicolumn{2}{|c|}{ Premature } \\
\hline & Lived & Died & Lived & Died \\
\hline Tokyo S University & $\begin{array}{l}38 \\
67\end{array}$ & $\begin{array}{r}29 \\
(43.3 \%)\end{array}$ & & 2 \\
\hline Tokyo TB University & $\begin{array}{l}21 \\
35\end{array}$ & $\begin{array}{r}14 \\
(\$ 0.0 \%)\end{array}$ & & 1 \\
\hline Aomori H University & $\begin{array}{l}5 \\
9\end{array}$ & $(44.4 \%)^{4}$ & & \\
\hline Tokyo E Hospital & $\begin{array}{l}41 \\
48\end{array}$ & $\begin{array}{r}7 \\
(12.5 \%)^{7}\end{array}$ & & 1 \\
\hline $\begin{array}{l}\text { Tokyo Mother \& Children } \\
\text { Hospital }\end{array}$ & $\begin{array}{l}31 \\
38\end{array}$ & $(18.4 \%)^{7}$ & $\begin{array}{r}8 \\
12\end{array}$ & $(33.3 \%)$ \\
\hline Total & 197 & $(31.5 \%)$ & 16 & $(50.0 \%)$ \\
\hline
\end{tabular}

(Author's findings)

TABLE 4: Prognosis of pneumonia in mewborn and premature babies in accordance with antibiotic used (Mother \& children Healith Care Center of Tokyo: 19 Cases).

\section{Antibiotics \&} administration methods

\begin{tabular}{|c|c|c|}
\hline \multicolumn{2}{|c|}{ Newborn } & Premature \\
\hline Lived & Died & Lived \\
\hline
\end{tabular}

CP, TC, PC

15

6

$(71.4 \%) \quad(28.6 \%)$

$4: 3$

Injection or Oral

$(57.0 \%) \quad(13 \%)$

Coxacillin

$16 \quad 1$

Injection

$(94.1 \%) \quad(5.9 \%)$

$\begin{array}{cc}4 & 0 \\ (100 \%) & (0)\end{array}$


Chronological changes in death rate of newbonns, infants and children. (Deaths in $1250=100)$.

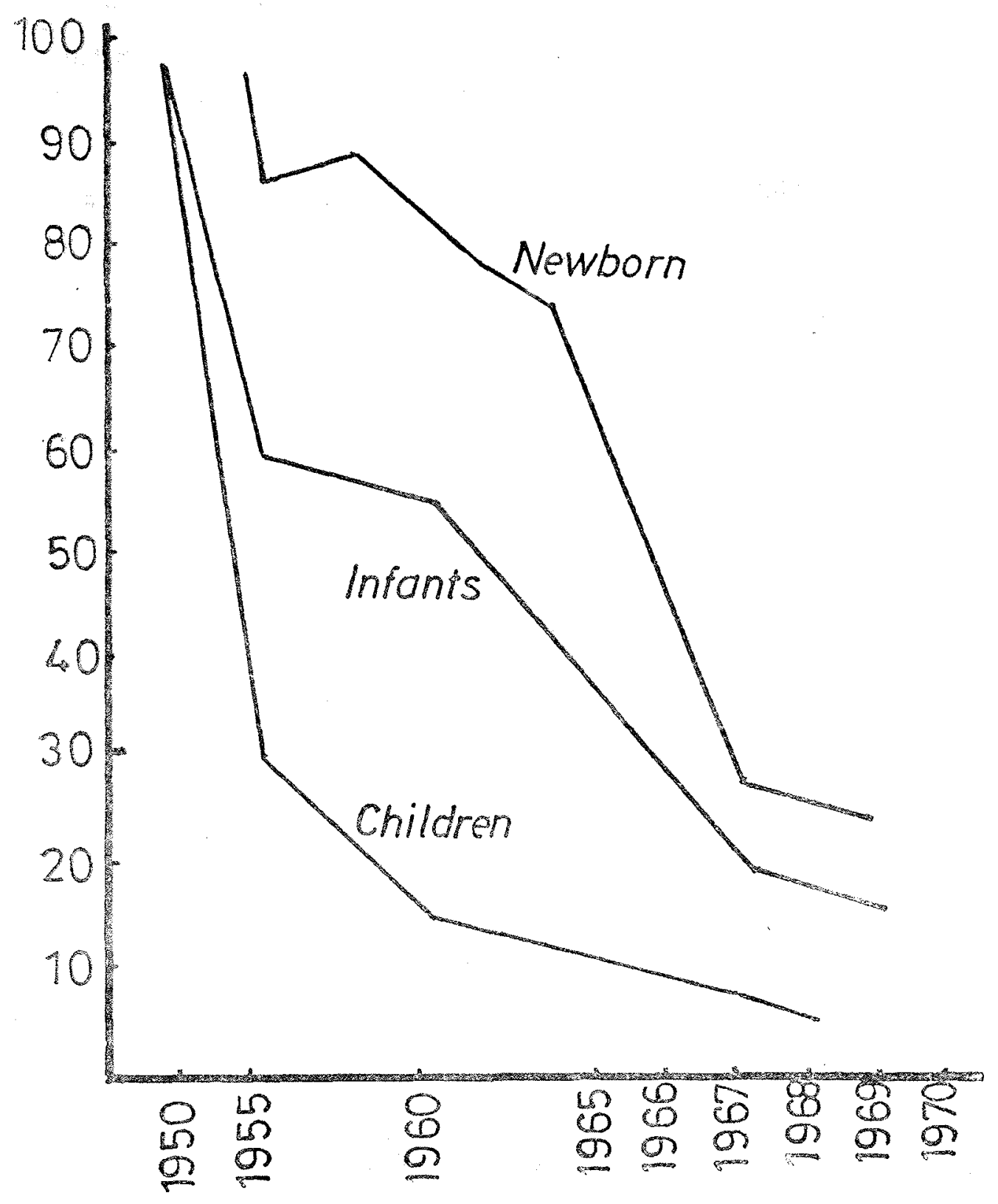


TABLE 6: Effectiveness of Vicillims $S$ against Pnenmonia in newborn and infants.

\begin{tabular}{|c|c|c|c|c|c|}
\hline \multirow[b]{2}{*}{ Cases } & \multicolumn{3}{|c|}{ Vicillin $\mathrm{S}$ injections } & \multicolumn{2}{|c|}{ Prognosis } \\
\hline & $\begin{array}{l}\text { One dose } \\
\text { (mg) }\end{array}$ & $\begin{array}{l}\text { Daily dosage } \\
\text { (mg) }\end{array}$ & Duration & Lived & Died \\
\hline \multirow[t]{2}{*}{54} & \multirow{2}{*}{$100-250$} & \multirow{2}{*}{$200-750$} & \multirow{2}{*}{$7-15$ days } & 48 & 6 \\
\hline & & & & \multicolumn{2}{|c|}{$\begin{array}{c}\text { Effectiveness } \\
88 \%\end{array}$} \\
\hline
\end{tabular}

TABLA 7: Drug Resistance of Sitaphylocaccus aureus in Japan (1965 3844 Strains).

\begin{tabular}{cc}
\hline (Antibiotics) & \multicolumn{1}{c}{ (Resistant strains) } \\
\hline SA & $86 \%$ \\
PcG & $69.1 \%$ \\
SM & $28.7 \%$ \\
TC & $34.9 \%$ \\
CP & $15.4 \%$ \\
EM & $20.5 \%$ \\
NB & $5.5 \%$ \\
DMP & $2.1 \%$ \\
KM & $4.7 \%$ \\
& \\
\hline
\end{tabular}

